\title{
Sensorineural hearing loss in patients with chronic suppurative otitis media: Is there a significant correlation?
}

\author{
Amin Amali ${ }^{1}$, Nima Hosseinzadeh ${ }^{2}$, Shahram Samadi ${ }^{3}$, Shirin Nasiri ${ }^{2}$, Jayran Zebardast ${ }^{4}$
}

${ }^{1}$ Associate Professor of Otorhinolaryngology, Otorhinolaryngology Research Center, Tehran University of Medical Sciences, Tehran, Iran

${ }^{2}$ Medical Student, Faculty of Medicine, Tehran University of Medical Sciences, Tehran, Iran

${ }^{3}$ Assistant Professor, Department of Anesthesiology and Intensive Care, Faculty of Medicine, Tehran University of Medical Sciences, Tehran, Iran

${ }^{4}$ Researcher Nurse, Deputy of research, Imam Khomeini Hospital, Tehran University of Medical Sciences, Tehran, Iran

\section{Type of article: Original}

\begin{abstract}
Introduction: Hearing loss as a sequel of chronic suppurative otitis media (CSOM) is often conductive, but recent studies have found an additional sensorineural component in these patients, thus demonstrating inner ear damage. The aim of the study was to determine the association between CSOM and sensorineural hearing loss (SNHL) and to assess the influence of patient's age, duration of disease, and presence of cholesteatoma and ossicular erosion on the degree of SNHL.

Methods: In a retrospective study, the medical records of 119 patients who underwent surgery was reviewed. Seventy patients met the inclusion criteria of unilateral otorrhea, normal contralateral ear on otoscopy, and age between 10-65 years with no history of head trauma or ear surgery or familial hearing loss. Bone conduction (BC) thresholds for affected and contralateral ear were measured at frequencies of 500, 1000, 2000, and $4000 \mathrm{~Hz}$. Data analysis was performed using SPSS 13 with independent-samples t-test, Pearson correlation test, and twotailed analysis. A $p \leq 0.05$ was considered statistically significant.

Results: Significant higher BC thresholds were found in the affected ear than in the normal ear for each frequency $(\mathrm{p}<0.001)$, which increased with increasing frequency $(7.00 \mathrm{~dB}$ at the $500 \mathrm{~Hz}$ and $9.71 \mathrm{~dB}$ at the 4000 $\mathrm{Hz})$. There was a significant correlation between age and degree of SNHL $(r=0.422, p<0.001)$ but no significant correlation was in duration of the disease $(\mathrm{r}=0.119, \mathrm{p}>0.05)$. There was no relationship between presence of cholesteatoma and ossicular erosion with SNHL ( $p>0.05)$.

Conclusion: These findings demonstrate that CSOM is associated with some degree of SNHL and cochlear damage, and higher frequencies are more affected. Aging can act as a precipitating factor in this pathological process.

Keywords: Hearing loss, Sensorineural, Otitis media, Suppurative, Bone conduction
\end{abstract}

\section{Introduction}

\subsection{Background}

Chronic suppurative otitis media (CSOM) is the chronic inflammation of the middle ear fossa with discharge through a perforated tympanic membrane. CSOM is the most chronic infectious disease in children (1) and is considered the leading cause of acquired hearing loss (2). Hearing loss is a public health problem in developed and developing countries. In the United States, 48.1 million or $20.3 \%$ of the population older than 12 years have unilateral or bilateral hearing loss (3). Hearing loss causes impaired language development and speech skills in children and poorer life quality and psychological problems for adults $(2,4)$.

\section{Corresponding author:}

Shahram Samadi, Department of Anesthesiology and Intensive Care, Faculty of Medicine, Tehran University of Medical Sciences, Tehran, Iran. Tel: +98.2161192828, Fax:+98.2166581537, Email: sh_samadi@sina.tums.ac.ir Received: August 12, 2016, Accepted: January 11, 2017, Published: February 2017

iThenticate screening: January 11, 2017, English editing: February 01,2017, Quality control: February 09, 2017

(C) 2017 The Authors. This is an open access article under the terms of the Creative Commons Attribution-NonCommercialNoDerivs License, which permits use and distribution in any medium, provided the original work is properly cited, the use is non-commercial and no modifications or adaptations are made. 


\subsection{Statement of problem}

Tympanic membrane rupture and ossicular chain changes often result in conductive hearing loss in CSOM (5). Recently numerous studies have reported an additional sensorineural hearing loss (SNHL) in these patients, demonstrating impaired cochlear function (5-7). Kaur et al. (8) and De Azevedo et al. (9) found a $24 \%$ and $13 \%$ incidence of SNHL in CSOM patients, respectively. Several studies also have investigated the correlation between SNHL with patient's age, duration of the disease, and presence of cholesteatoma and ossicular erosion. Kolo et al. (10) found a significant degree of SNHL in patients with CSOM, but the patient's age and duration of otorrhea did not have any correlation with it. Raqib (11) and Kaur (8) observed a significant relationship between SNHL and the disease duration.

\subsection{Objective of research}

The objective of the current study was to evaluate the association between CSOM and SNHL in patients who underwent surgery in a tertiary referral university hospital, Tehran, Iran, between 2011 and 2013. We also aimed to assess the correlation among patient's age, duration of disease, and presence of cholesteatoma and ossicular erosion with the degree of SNHL.

\section{Material and Methods}

\subsection{Research design and participants}

A cross-sectional study was carried out from April 2011 to March 2013 in Tehran, Iran. The medical records of patients who underwent middle ear surgery in the Imam Khomeini Hospital complex, Valiasr Hospital, were evaluated. Patients were recruited based on the following inclusion criteria: 1) presence of unilateral otorrhea lasting at least for 3 months and tympanic membrane perforation on otoscopy; 2) normal tympanic membrane in contralateral ear based on otoscopy; 3) patients with age ranging from 10-65 years. Patients were excluded if they had a history of head trauma or traumatic tympanic membrane perforation, meningoencephalitis, chronic exposure to noise, prior ear surgery, previous ototoxic drug therapy, and family history of congenital or acquired hearing loss.

\subsection{Measurement tool and data collection}

Demographic variables, duration of the disease, main symptoms, and pure tone audiometry (12) results were obtained from the patients' medical records by a qualified otorhinolaryngologist and recorded in valid and reliable data forms. To define the presence of cholesteatoma and ossicular erosion, we assessed the reports of the operation and direct observation of the surgeon. Bone conduction (BC) hearing thresholds for both diseased and control ear at frequencies 500, 1000, 2000, and $4000 \mathrm{~Hz}$ were extracted to determine the SNHL.

\subsection{Ethical consideration}

The institutional review board of our university approved this study and aspects of its research ethics (registration number: 21853). Patients' information during and after the study remained confidential.

\subsection{Statistical analysis}

Data analysis was performed using SPSS 13 (SPSS Inc., Chicago, Illinois, United States of America). Independentsamples t-test was used to evaluate differences between bone-conduction thresholds for affected and control ears for each patient. A Pearson correlation test was used to determine the association among age, duration of disease, and degree of SNHL as well. Two-tailed analysis was applied for all of these tests, and a $p \leqslant 0.05$ was considered statistically significant.

\section{Results}

The medical records of 119 patients were reviewed, and only 88 patients met the inclusion criteria. Twelve patients excluded because of the previous ear surgery, six patients had history of trauma, family history of hearing loss, and incomplete medical records. Seventy patients, including 36 females (51.4\%) and 34 males (48.6\%) with mean age \pm SD of $37.9 \pm 15$ years (ranging from 11 to 65 years), were selected for analysis. Mean duration \pm SD of the disease was $6.5 \pm 7.06$ years ranging from 3 months to 30 years. Most common symptoms of the patients were hearing loss (94.3\%), Otorrhea (81.4\%), tinnitus (37.1\%), otalgia (27.1\%), and vertigo (12.9\%). The mean BC threshold in the affected ear was $21.41 \mathrm{~dB}(\mathrm{SD}=15.95)$, and $13.21 \mathrm{~dB}(\mathrm{SD}=10.29)$ in the normal ear $(\mathrm{p}<0.001)$. Table 1 shows paired bone-conduction threshold averages for the affected and normal ears across the frequencies $(500,1000,2000$, and $4000 \mathrm{~Hz}$ ). There were higher thresholds in the affected ear than in the normal ear for each frequency. All of them were statistically significant $(\mathrm{p}<0.001)$ The mean $\mathrm{BC}$ threshold differences between affected and normal ears range from 7.00 to $9.71 \mathrm{~dB}$ across the frequencies, which tend to increase with increasing frequency. A significant 
correlation between the patients' age and degree of SNHL was observed across the tested frequencies $(\mathrm{r}=0.295, \mathrm{p}=$ $0.013 ; \mathrm{r}=0.398, \mathrm{p}=0.001 ; \mathrm{r}=0.287, \mathrm{p}=0.016 ; \mathrm{r}=0.497, \mathrm{p}<0.001$ for the frequencies $500,1000,2000$ and 4000 respectively. $r=0.422, p<0.001$ for mean of them). Although the correlation between duration of the disease and degree of SNHL was investigated, no statistically significant correlation was found between them $(r=0.041, p>$ $0.05 ; \mathrm{r}=0.081, \mathrm{p}>0.05, \mathrm{r}=0.126, \mathrm{p}>0.05 ; \mathrm{r}=0.161, \mathrm{p}>0.05$ for the frequencies 500, 1000, 2000, and 4000 respectively. $r=0.119, \mathrm{p}>0.05$ for mean of them). Eight patients $(11.4 \%)$ had cholesteatoma in their surgical reports. Table 2 shows mean $\mathrm{BC}$ threshold differences between the affected and normal ears based on the presence of cholesteatoma. No significant difference was found between ears with or without cholesteatoma across all frequencies $(\mathrm{p}>0.05)$. Ossicular erosion was seen in 13 patients $(18.6 \%)$. Table 3 shows the affected ears divided on the basis of the presence or absence of ossicular erosion. No significant difference was observed in mean BC threshold differences between those with or without cholesteatoma across the tested frequencies $(p>0.05)$.

Table 1. Paired bone-conduction threshold averages for the affected and normal ears

\begin{tabular}{|l|c|c|c|}
\hline \multirow{2}{*}{ Frequency $(\mathrm{Hz})$} & \multicolumn{2}{|l|}{ Bone conduction thresholds } & p-value \\
\cline { 2 - 4 } & Affected ear & Normal ear & \\
\hline 500 & $17.57 \pm 13.93^{\mathrm{a}}$ & $10.57 \pm 9.07$ & $<0.001$ \\
\hline 1000 & $18.36 \pm 16.30$ & $10.81 \pm 9.96$ & $<0.001$ \\
\hline 2000 & $21.71 \pm 16.92$ & $13.21 \pm 12.10$ & $<0.001$ \\
\hline 4000 & $28.00 \pm 21.42$ & $18.29 \pm 14.77$ & $<0.001$ \\
\hline
\end{tabular}

${ }^{\mathrm{a}}$ Mean \pm Standard Deviation

Table 2. Mean BC threshold differences between the ears based on the presence of cholesteatoma

\begin{tabular}{|l|l|l|l|}
\hline \multirow{2}{*}{ Frequency $(\mathrm{Hz})$} & \multicolumn{2}{|l|}{ Mean BC threshold difference } & \multirow{2}{*}{-value } \\
\cline { 2 - 3 } & Without cholesteatoma $(\mathrm{n}=62)$ & With cholesteatoma $(\mathrm{n}=8)$ & \\
\hline 500 & 7.34 & 4.37 & 0.489 \\
\hline 1000 & 8.11 & 3.12 & 0.286 \\
\hline 2000 & 8.63 & 7.5 & 0.815 \\
\hline 4000 & 10.24 & 5.62 & 0.418 \\
\hline
\end{tabular}

Table 3. Mean BC threshold differences between the ears based on the presence of ossicular erosion

\begin{tabular}{|l|l|l|l|}
\hline \multirow{2}{*}{ Frequency $(\mathrm{Hz})$} & \multicolumn{2}{|l|}{ Mean BC threshold difference } & \multirow{2}{*}{ p-value } \\
\cline { 2 - 3 } & Without ossicular erosion $(\mathrm{n}=57)$ & With ossicular erosion $(\mathrm{n}=13)$ & \\
\hline 500 & 7.37 & 5.38 & 0.572 \\
\hline 1000 & 7.63 & 7.15 & 0.901 \\
\hline 2000 & 8.68 & 7.69 & 0.801 \\
\hline 4000 & 10.35 & 6.92 & 0.463 \\
\hline
\end{tabular}

\section{Discussion}

Although several studies have proposed the association between CSOM and SNHL, there is still lack of consensus about its importance. In the current study, we investigated the medical records of the CSOM patients to evaluate the association among SNHL and CSOM, age, duration of otorrhea, and presence of cholesteatoma and ossicular erosion. A significant increase was found in $\mathrm{BC}$ thresholds in the diseased ear in comparison with the normal ear across the speech frequencies $(500,1000,2000$, and $4000 \mathrm{~Hz})$. There was a greater difference in the high frequencies than in the low frequencies $(7.00 \mathrm{~dB}$ at $500 \mathrm{~Hz}$ increasing to $9.71 \mathrm{~dB}$ at $4000 \mathrm{~Hz}$ ). Our findings comply with those found by Noordzij et al. (13) and Levine et al. (14). In a similar study, MacAndie and O'Reilly (6) found a significant degree of SNHL in the diseased ear, which tended to be increased in higher frequencies. The se findings supports the hypothesis that proposes middle ear inflammation may change the permeability of round window membrane, so remnants of the bacteria such as endotoxins could pass through it and cause dysfunction of the inner ear, especially in high-frequency region anatomically located close to the round window $(15,16)$. A direct and strongly significant correlation was observed between patients' age and the degree of SNHL $(r=0.422, p<0.001)$. Redaelli et al. (17) and Vartiainen (18) also have reported similar findings. It seemed that older patients are more vulnerable to the effects of middle ear inflammation on cochlear function, and this can intensify hearing impairment due to aging. Age-related hearing loss (ARHL) or presbycusis is one of the most common disabilities in elderly people, which affects approximately $27.6 \%$ of individuals between 65 to 79 years and $36.5 \%$ of those aged 80 and older (19). To decrease the effect of ARHL, we excluded patients older than 65 years and considered the mean BC 
threshold differences for analysis because presbycusis often cause bilateral and symmetric hearing loss. There was no significant correlation between duration of otorrhea and degree of SNHL. $(r=0.119, p>0.05)$. Our findings are consistent with those found in several studies $(6,10,13)$. In contrary, Papp (20) found that bone conduction threshold at either the speech frequencies or at $4 \mathrm{kHz}$ increased gradually according to the duration of the CSOM. In a study with similar methodology, SNHL was progressively increased with increasing the CSOM duration (8).

Comparison of the ears with and without cholesteatoma showed no significant association between presence of cholesteatoma and SNHL; nevertheless, there were only eight patients with cholesteatoma and such number of patients might be not enough to judge about it. This concurs with the findings of MacAndie (6) and de Azevedo (9). Although the number and proportion of CSOM patients with cholesteatoma in their studies was greater than our study, they found no difference in SNHL between patients with or without cholesteatoma. The present study did not demonstrate a significant relation between ossicular erosion and severity of SNHL ( $p>0.05$ ), but Levine et al. (14) found significant association with the presence of ossicular erosion and SNHL. We used a strict criterion to decrease the effect of confounding factors, but we could not exclude patients using topical ototoxic antibiotics. Medications such as topical aminoglycosides are commonly used for treatment of otitis, and nearly all patients have used them before ear surgery. There is still controversy about their toxicity and effects on cochlear function. In the investigations of Lundy and Graham about toxicity of ototopical medications, from 2235 otolaryngologists only $3.4 \%$ reported irreversible inner ear damage. Also $80 \%$ of respondents mentioned that the risks for ototoxicity of otitis media is greater than using ototopical preparations (21) Browning et al. (22) used gentamicin in their investigations on adults with chronic otitis media and found no evidence of ototoxic inner ear damage. The difference found in $\mathrm{BC}$ thresholds between the affected and normal ear is significant but small. This difference only demonstrates the audiometric changes and might have a negligible influence on patient's hearing in comparison with the changes in tympanic membrane and ossicular chains. Further studies are needed to elucidate this subject. In addition, the Carhart's effect must be considered when dealing with bone conduction thresholds in chronically infected ears. In chronic otitis media, mechanical occlusion of the window by granulations, cholesteatoma and pus, or stiffness of the ossicular chain may result in loss of bone conduction (23).

\section{Conclusions}

A significant association between SNHL and CSOM was found in this study. The difference in BC thresholds increased with increasing frequency. Patients' age was significantly correlated with the degree of SNHL, but no significant association was observed between SNHL with duration of disease and presence of cholesteatoma and ossicular erosion. However, these findings demonstrate significant audiometric cochlear damage, clinical relevancy should be evaluated in future studies.

\section{Acknowledgments:}

Tehran University of Medical Sciences and Health Services Grant supported this study, and this article was extracted from a thesis prepared by Mr. Nima Hosseinzadeh.

\section{Conflict of Interest:}

There is no conflict of interest to be declared.

\section{Authors' contributions:}

All authors contributed to this project and article equally. All authors read and approved the final manuscript.

\section{References:}

1) Verhoeff M, van der Veen EL, Rovers MM, Sanders EA, Schilder AG. Chronic suppurative otitis media: a review. Int J Pediatr Otorhinolaryngol. 2006; 70(1): 1-12. doi: 10.1016/j.ijporl.2005.08.021. PMID: 16198004.

2) Jensen RG, Koch A, Homoe P. The risk of hearing loss in a population with a high prevalence of chronic suppurative otitis media. Int J Pediatr Otorhinolaryngol. 2013; 77(9): 1530-5. doi: 10.1016/j.ijporl.2013.06.025. PMID: 23906989.

3) Lin FR, Niparko JK, Ferrucci L. Hearing loss prevalence in the United States. Arch Intern Med. 2011; 171(20): 1851-2. doi: 10.1001/archinternmed.2011.506. PMID: 22083573, PMCID: PMC3564588.

4) Bakir S, Kinis V, Bez Y, Gun R, Yorgancilar E, Ozbay M, et al. Mental health and quality of life in patients with chronic otitis media. Eur Arch Otorhinolaryngol. 2013; 270(2): 521-6. doi: 10.1007/s00405012-2031-6. PMID: 22566178. 
5) da Costa SS, Rosito LP, Dornelles C. Sensorineural hearing loss in patients with chronic otitis media. Eur Arch Otorhinolaryngol. 2009; 266(2): 221-4. doi: 10.1007/s00405-008-0739-0. PMID: 18629531.

6) MacAndie C, O'Reilly BF. Sensorineural hearing loss in chronic otitis media. Clin Otolaryngol Allied Sci. 1999; 24(3): 220-2. PMID: 10384849.

7) Paparella MM, Morizono T, Le CT, Mancini F, Sipilä P, Choo YB, et al. Sensorineural hearing loss in otitis media. Ann Otol Rhinol Laryngol. 1984; 93(6 Pt 1): 623-9. PMID: 6508134.

8) Kaur K, Sonkhya N, Bapna AS. Chronic suppurative otitis media and sensorineural hearing loss: Is there a correlation? Indian J Otolaryngol Head Neck Surg. 2003; 55(1): 21-4. doi: 10.1007/BF02968747. PMID: 23119929, PMCID: PMC3450943.

9) de Azevedo AF, Pinto DC, de Souza NJ, Greco DB, Goncalves DU. Sensorineural hearing loss in chronic suppurative otitis media with and without cholesteatoma. Braz J Otorhinolaryngol. 2007; 73(5): 671-4. PMID: 18094809.

10) Kolo ES, Salisu AD, Yaro AM, Nwaorgu OG. Sensorineural hearing loss in patients with chronic suppurative otitis media. Indian J Otolaryngol Head Neck Surg. 2012; 64(1): 59-62. doi: 10.1007/s12070011-0251-5. PMID: 23449378, PMCID: PMC3244579.

11) Raquib A, Taous A, Haque R. Sensorineural component in chronic suppurative otitis media. Bangladesh Journal of Otorhinolaryngology. 2009; 15(2): 69-74. doi: 10.3329/bjo.v15i2.5060.

12) Varshney S, Nangia A, Bist SS, Singh RK, Gupta N, Bhagat S. Ossicular chain status in chronic suppurative otitis media in adults. Indian J Otolaryngol Head Neck Surg. 2010; 62(4): 421-6. doi: 10.1007/s12070-010-0116-3. PMID: 22319706, PMCID: PMC3266081.

13) Noordzij JP, Dodson EE, Ruth RA, Arts HA, Lambert PR. Chronic otitis media and sensorineural hearing loss: is there a clinically significant relation? Am J Otol. 1995; 16(4): 420-3. PMID: 8588640.

14) Levine BA, Shelton C, Berliner KI, Sheehy JL. Sensorineural loss in chronic otitis media. Is it clinically significant? Arch Otolaryngol Head Neck Surg. 1989; 115(7): 814-6. PMID: 2736092.

15) Spandow $O$, Anniko M, Hellstrom $S$. Inner ear disturbances following inoculation of endotoxin into the middle ear. Acta Otolaryngol. 1989; 107(1-2): 90-6. PMID: 2648747.

16) Goycoolea MV, Paparella MM, Juhn SK, Carpenter AM. Oval and round window changes in otitis media. Potential pathways between middle and inner ear. Laryngoscope. 1980; 90(8 Pt 1): 1387-91. PMID: 6967546.

17) Redaelli de Zinis LO, Campovecchi C, Parrinello G, Antonelli AR. Predisposing factors for inner ear hearing loss association with chronic otitis media. Int J Audiol. 2005; 44(10): 593-8. PMID: 16315450.

18) Vartiainen E, Vartiainen J. Age and hearing function in patients with chronic otitis media. J Otolaryngol. 1995; 24(6): 336-9. PMID: 8699598.

19) Caban AJ, Lee DJ, Gomez-Marin O, Lam BL, Zheng DD. Prevalence of concurrent hearing and visual impairment in US adults: The National Health Interview Survey, 1997-2002. Am J Public Health. 2005; 95(11): 1940-2. doi: 10.2105/AJPH.2004.056671. PMID: 16195516, PMCID: PMC1449463.

20) Papp Z, Rezes S, Jokay I, Sziklai I. Sensorineural hearing loss in chronic otitis media. Otol Neurotol. 2003; 24(2): 141-4. PMID: 12621323.

21) Lundy LB, Graham MD. Ototoxicity and ototopical medications: a survey of otolaryngologists. Am J Otol. 1993; 14(2): 141-6. PMID: 8503487.

22) Browning GG, Gatehouse S, Calder IT. Medical management of active chronic otitis media: a controlled study. J Laryngol Otol. 1988; 102(6): 491-5. PMID: 3294318.

23) Vartiainen E, Karjalainen S. Factors influencing sensorineural hearing loss in chronic otitis media. Am J Otolaryngol. 1987; 8(1): 13-5. PMID: 3578673. 